\title{
The Exploration of University Open Laboratory Based on Innovation Concept
}

\author{
Dingzhu Xue ${ }^{1, a^{*}}$ and Pei Xiao ${ }^{1, b}$ \\ ${ }^{1}$ JiLin Agricultural University, ChangChun, 130118, China \\ a9950502@qq.com, b4566254@qq.com
}

\section{Keywords: Open Laboratory; Innovation; Exploration}

\begin{abstract}
This paper analyzes the common problems existing in the present university Laboratory. The aim is to construct an innovation-oriented University Open Laboratory. In the establishment mode of this laboratory, on the one hand, the university should centralize the management; each branch college laboratory should be used as services unit to fully develop students' awareness of independent innovation and break the institute disciplinary barriers by free combination. On the other hand, project investment should be used as a funding body, while the risk investment concept should be introduced to maintain the students' enthusiasm of innovation and maximize the utilization of funding. The open degree of each laboratory should be strengthened. Moreover, supervision and reward mechanism should be made. Therefore, teachers can instruct students' innovative activities by the application of reward and punishment system.
\end{abstract}

\section{Introduction}

Cultivating innovative talents and constructing the innovation system has become an important part of national development strategy. Innovation is a conceptual process characterized with the new thinking and new perspective. The cultivation of innovative consciousness requires an open environment, encouraging the students' bold attempt. Laboratory is the main place of college students' practical ability training and a key battleground for training innovative talents. Opening laboratory is the basis and starting point of cultivating innovative talents. But it is a complex project, involving time, content, students, teachers and other factors. At present, most of the open laboratories in the universities are considered the branch college and profession as the unit, with experimental courses and various competitions as the main body. It opens only towards the students in this unit, which is far away from the so- called innovation. This paper takes the innovation as the guidance, constructing an open laboratory system mainly managed by the school.

\section{The Defects Existing in the Current University Open Laboratory}

At present, most of the open laboratories in colleges and universities are based on the original experiments of the colleges. The experimental courses on this laboratory are open to students, providing some venues and corresponding equipment for students' competitions and extracurricular activities. However, this is not an open laboratory. At most, it can be called the opening of the laboratory. In varying degrees, there are many problems and shortcomings in the laboratory. So some common problems will be proposed in the following illustration. [1-2].

First, the content of open laboratory is too single. It lacks the overall harmony, without the cross-disciplinary ability to solve problems. First, the current open laboratory is based on the time and instrument opening of the original laboratory. Furthermore, the open content is also based on curriculum experiments. When the students do not have a good experience after the church, they have a chance to make up for themselves. But when the students have their own ideas and intend to implement them, they find that they cannot find an experimental place. Especially when it comes to 
interdisciplinary, the students do not know where to realize their own ideas. This greatly restricts the development of the students' independent innovation [3-4].

Second, there is the lack of special funds to support open laboratory. Because the management of open laboratory is carried out by the branch colleges themselves, only the part of the funds for the experiment is used for opening. The division of the funds is not clear. So if it needs certain funds when opening, it will be often stopped because of no funds support.

Third, there is lack of open laboratory technical instructors. Most teachers feel that there is little or no relationship between the innovation cultivation and themselves. However, the innovation as a necessary capacity for the future college students should be developed by the joint efforts of all the teachers. A lot of students have their own unique ideas, but they do not have the ability to achieve it. So it requires the guidance of teachers. Especially in some interdisciplinary research, the guidance of different professional teachers and technical support becomes more important.

\section{Centralized Mode Open Laboratory}

The focus of open laboratory management is to optimize the interconnection of laboratory resources, stimulate students' innovative potential, promote the establishment of interdisciplinary research team, and promote the mutual penetration of production and research, reaching a virtuous circle of innovative talents. However, it can't be achieved only by standing on a discipline or an academic point of view. So there should be a higher point to support it. To establish an open laboratory based on school-centralized model, the experimental resources should be integrated, the open system should be developed and the management funding should be input.

Integration of Laboratory Resources. The college laboratory settings are based on the experimental mode of the course. There are a large number of interdisciplinary courses among the branch colleges, so a large number of repeated laboratories appear. It causes the utilization of laboratory is not high. Maybe a laboratory can be used only three weeks or four weeks a year, resulting in waste of resources. First of all, the laboratory should be merged.

The university should redefine each laboratory according to their function. Even a single experimental project should be checked. The laboratories with high repetition rate for utilization should be merged. The laboratories with low utilization should be merged in Branch College. The laboratories of low utilization with large size equipment requiring special circumstances which cannot be merged should be reported to the school. The school should form an expert group to assess it. If the assessment is passed, the laboratories can be retained. If not, the related branch college will be held responsible. Second, the branch colleges should integrate their own resources and the existing technical capabilities, proposing the existing tasks that can be accomplished for opening.

Improve the Open Mechanism to Create a Good Soft Environment. The current opening is the opening of the subject or the branch college. Although it opens towards the whole school or the society, there is no appropriate application process and specific organization responsible for the matter. This opening is only the internal opening, not a complete opening, greatly limiting the interdisciplinary cooperation and a lot of good ideas for innovation. It's also harmful for innovation training.

The new open laboratory will create an open software platform. The integrated experimental resources of the whole school and the task each laboratory can complete will be linked to this platform, so the students can select one or more laboratories for innovation activities according to their own innovative ideas. The system will arrange time for students to enter the appropriate laboratory and notify the relevant branch college where the laboratory, asking them to cooperate and guide students. 


\section{Open Funds Management}

At present, the funds of open laboratory and experiment are mixed with that of the college. The division is unclear. Even some don't have these funds. Little money restricts the opening of the laboratory and the innovation activities. The funds for the new open experiment will be allocated directly to the laboratory by the school, with the project financing as the main mode of distribution. At the same time, the venture capital mechanism will be introduced and carried out.

Open funds are mainly invested in the form of investment projects to form a team of innovation and investment. Students should set up their own innovation team to get funding and select a team leader. First, the team leader is responsible for all matters within the team. Then, the team puts forward their own innovative projects written in the form of plans. In the plans, there should be preliminary research, feasibility research, the analysis of the team composition, the ability to complete the project, the research schedule, the budget in different periods. It should be recommended by three related teachers. The design book is submitted to the open laboratory through an open application software platform, which is distributed by the laboratory to the relevant experts for evaluation and approval. The funds are distributed according to the budget in each stage of the plan. The team leader is responsible for the usage of the funds and submits the results on time. If the research results of the completion do not meet the objectives of this stage, or the remaining funds is more than $30 \%$, the funding of next phase will be suspended. If the desired objectives cannot be completed for more than three months, the project will be banned. Moreover, the team leader's name will be put into the open application dishonest list. At the same time, certain credits will be deducted according to the situation.

The venture capital mechanism should be introduced. If the innovation application is not approved, but the program is feasible, self-financing and pre-investment can be done. If the expected target can be completed more than 50\% according to the plan, the application of funds from the open laboratory can be done again without evaluation. Pre-investment can also be applied for reimbursement.

\section{Establish Reward and Punishment System and Promote Teachers and Students to Participate in Innovation Activities}

Students and teachers as the main elements of the open laboratory are the soul of innovation. Only their commitment to the activities of innovation with high enthusiasm, it can make the open laboratory have more vitality. More innovative talents can also be cultivated. But the enthusiasm of teachers and students of innovation is generally not high. The reason is that the atmosphere of innovation is not strong, the corresponding incentive measures are not made, the innovation ability is not cultivated as a college student should have. Therefore, we should establish a set of incentives for students and teachers to participate in innovative activities of the system.

Reward and punishment system can be divided into two aspects, students and teachers. Students: Make the innovative credits written into the various professional training programs, according to different disciplines to set a considerable proportion of innovative credits. Students who participate in the innovation program receive credits based on their role in their respective teams. The credit can be used as an innovative credit and can be converted into general credits for inclusion in the student's total credits. . Innovative scholarships are established to reward outstanding students in innovative activities. Students who have outstanding performance in the innovation activities are also eligible for postgraduate or doctoral degrees. Teachers: Make the development of innovative class standards. Each teacher completes a certain amount of innovation according to the title of academic qualifications. The amount of work done by the teacher depends on the amount of their guidance to the students' completion of innovative activities. Teachers who have overtaken the innovation class can be increased the allowance. If they did not complete the standard amount of work, the allowance will be reduced. At the same time, the teachers participating in innovation activities can be promoted 
in title. Exceptional promotion appointment should be given to the teachers who make an outstanding performance in the innovation activities.

\section{Conclusions}

The establishment of an open laboratory based on innovation is an important means to cultivate new and innovative talents in modern colleges and universities. It is an exploration and practice of a new open laboratory model and a complex and arduous project. It is the management and operation reform of the current general university open laboratory. It can optimize the resources of the laboratory, further break the barrier between the academic colleges, maximize the use of funds, stimulate the enthusiasm of teachers and students to promote innovation and interdisciplinary innovation team and cultivate outstanding innovative talents.

\section{Acknowledgements}

Funds for the research were provided by Jilin province university undergraduate science and technology innovation fund. National university undergraduate science and technology innovation fund (No.201510193043). Scientific research fund of Jilin Agricultural University(No.201620).

\section{References:}

[1] LI Qiang. Exploration of management mode and operation mechanism of university laboratory based on open orientation [J].Journal of Experimental Technology and Management, 2013 (7): 228-231. (In Chinese).

[2] Li Tie, Li Ming, et al. Changes in the Open Teaching System of Innovative Laboratories [J]. Laboratory Research and Exploration, 2012 (9): 142-143. (In Chinese).

[3] Peng Ruwu, Xu Haihua. Laboratory opening and management of university practice and exploration [J]. Laboratory Science, 2013 (2): 129-132. (In Chinese).

[4] LI Mei-xuan. Application and practice of laboratory opening in science and engineering university [J] .Experimental Technology and Management, 2013 (3): 196-197. (In Chinese).

[5] Wu generation. Experimental technicians in the opening of the biochemical laboratory of Chinese medicine institutions in the role [J]. Chinese and foreign medical, 2013 (2): 140-141. (In Chinese). 